\title{
Understanding the "SEKKI" phenomena in Japanese historical literatures based on the modern science of low-latitude aurora
}

\author{
Yoh Nakazawa ${ }^{1}$, Toshimi Okada ${ }^{2}$, and Kazuo Shiokawa ${ }^{3}$ \\ ${ }^{1}$ Niigata Prefectural Maki High School, Maki, Niigata 953-0044, Japan \\ ${ }^{2}$ Faculty of Engineering, Toyama Prefectural University, Kosugi, Toyama 939-0398, Japan \\ ${ }^{3}$ Solar-Terrestrial Environment Laboratory, Nagoya University, Toyokawa, Aichi 442-8507, Japan
}

(Received August 24, 2004; Revised October 7, 2004; Accepted December 13, 2004)

\begin{abstract}
"SEKKI" phenomena often appear in the Japanese historical literatures as distinct red emission in the nocturnal sky. The Japanese word "SEKKI" means the red atmosphere. We compile 16 events of SEKKI for 12-19th centuries in the literatures. In order to understand the SEKKI phenomena, we compared 2 events of SEKKI on February 21, 1204, and September 17, 1770, with the characteristics of low-latitude auroras studied recently by modern scientific methods. We conclude that these historical SEKKI phenomena are probably giant low-latitude auroras.
\end{abstract}

Key words: SEKKI, low-latitude aurora, historical literatures, magnetic storm.

\section{Introduction}

Although the magnetic latitude of Japan is low, weak auroras have been sometimes observed in Japan during the high solar activity. Furuhata (1958) and Hikosaka (1958) reported an intense aurora observed at various places in Japan on February 11, 1958. Miyaoka et al. (1990) showed a spectacular red aurora observed in the northern part of Japan on October 21, 1989. From the recent routine measurements of highly sensitive optical instruments, Shiokawa et al. (2004) reported 19 events of low-latitude auroras during the solarmaximum period of 1998-2003. For three of them, the auroras were observed not only in Hokkaido (northern Japan, geomagnetic latitude $\sim 35^{\circ} \mathrm{N}$ ), but also in the central Japan (geomagnetic latitude $\sim 25^{\circ} \mathrm{N}$ ).

Not only these modern measurements, there are some historical literatures that suggest quite strong auroras appeared in Japan. The records on December 30, 620 and September 18 , 682, in "Nihon-Shoki" are probably the oldest records on the auroras. In this paper, we compile these historical documents that are likely to describe low-latitude auroras. They are often referred as "SEKKI" in the literatures. The word "SEKKI" in Japanese means the red atmosphere. We conclude on the basis of modern auroral measurements that some of the "SEKKI" phenomena in the old documents of Japan are the records of large-scale appearance of lowlatitude auroras.

\section{Characteristics of Low-Latitude Auroras based on Modern Observations}

There were 8 events of low-latitude auroras observed from Japan in Cycle-19 solar activity (Kakioka Magnetic Observatory, 1969), 11 events in Cycle-22 (Miyaoka et al., 1990; Saito et al., 1994; Shiokawa et al., 1994, 1995), and 19

Copy right (c) The Society of Geomagnetism and Earth, Planetary and Space Sciences (SGEPSS); The Seismological Society of Japan; The Volcanological Society of Japan; The Geodetic Society of Japan; The Japanese Society for Planetary Sciences; TERRAPUB events in Cycle-23 (Shiokawa et al., 2004). These auroras were observed during geomagnetic storms by optical detectors (photometers and all-sky imagers) and by naked eyes mostly in Hokkaido and some in the central Japan. The characteristics of the large-scale appearance of low-latitude auroras based on these observations in Japan (38 events) are as follows.

[The time of the appearance]

(1) The auroras occur around the maximum interval of solar activity.

(2) The auroras occur mainly in early spring and autumn.

Figure 1 shows seasonal dependence of the 38 events of low-latitude auroras of 1957-2003. In Japan, the sky condition is mostly good in winter and bad in summer, particularly for the pacific ocean side, where most of the aurora measurements was done. However no auroras were reported in December and January. The sky condition in May and September is mostly fair, but the auroral occurrence decreases compared with April and October. Thus, we can say that the low-latitude auroras are mostly observed in early spring and autumn in Japan. This seasonal variation is consistent with that of magnetic storms, which is often explained by the "Russell-McPherron" effect (Russell and McPherron, 1973) and Macintosh/Equinoxial Effect (Cliver et al., 2000).

[Conditions of appearance]

(3) The auroras appear in the main and recovery phase of magnetic storms. The recovery-phase auroras are often identified as Stable Auroral Red (SAR) arcs.

(4) The azimuthal (east-west) extent of the aurora reaches $90^{\circ}-120^{\circ}$ in the northern sky, in case of large-scale appearance.

(5) The dark red emission at a wavelength of $630 \mathrm{~nm}$ is the main emission from the aurora.

(6) The auroral shape is often unstable. Vertical lineshaped structures with yellow or white colors are often seen in case of large-scale appearance.

The yellow or white color is probably because of a mix- 


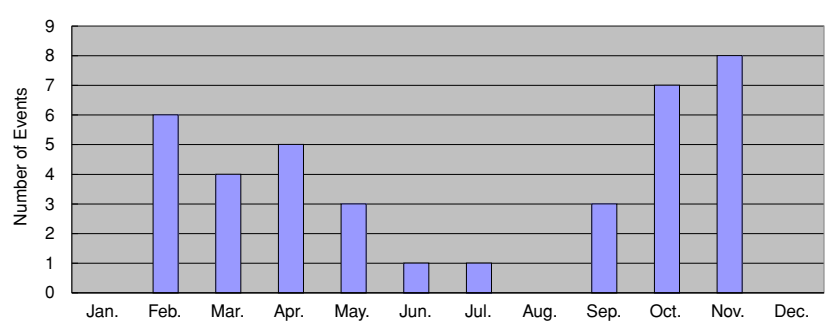

Fig. 1. Seasonal variation of low-latitude aurora occurrence in Japan in 1957-2003.

ture of different colors. According to the relations of the three primary colors of the light, red + green $=$ yellow, and red + green + blue $=$ white. Red $(630.0 \mathrm{~nm}$ and 636.4 $\mathrm{nm})$ and green $(557.7 \mathrm{~nm})$ are the emissions from oxygen atom (O) and blue $(391.4,427.8 \mathrm{~nm})$ is from the nitrogen molecule ion $\left(\mathrm{N}_{2}^{+}\right)$. The red (dark red) color is the major part of the low-latitude aurora. This red emission from oxygen atom is caused by a collision with relatively low-energy electrons (less than $100 \mathrm{eV}$ ). The green and blue emissions are by the high-energy particle precipitations as those in the high-latitude region. In case of strong low-latitude auroras, high-energy particles often precipitate in the low magnetic latitudes as well (Miyaoka et al., 1990; Okada et al., 1993; Shiokawa et al., 1997, 1999). A broad energy spectrum of precipitating particles can cause emission lines at various wavelengths at different altitudes. In case when aurora has a certain latitudinal width, the different colors at different altitudes would be mixed along the line of sight from ground observers.

\section{The SEKKI Phenomena}

\subsection{SEKKI records in 12-19th centuries}

Table 1 lists 16 examples of the historical documents for 12-19th centuries that seem to describe some sort of auroral emissions in the sky. For most of them, records of sunspots or auroras are available in the literatures of China on the same day or month. The aurora of No. 12 was seen in China and Eurore on the same day. The aurora of No.16 was observed in China, Cuba, Jamaica, and Hawaii as well (Kanda, 1935; Nakazawa, 1999; Ohsaki, 1994; Taguchi, 1939).

In this paper, we take two historical SEKKI events on February 21, 1204, and on September 17, 1770, to investigate the relations of SEKKI and low-latitude auroras. These two events were selected by considering secular geomagnetic variations and solar activity of 12-19th centuries on the basis of data of carbon14 and sunspot numbers. Namely, these two events occur during the maximum periods of solar activity (Stuiver et al., 1998; Masuda, 2000). The center of the auroral zone in the northern hemisphere was located around Greenland and northern Canada, like at present, on September 17, 1770, while it was closer to Japan (around the north geographic pole) on February 21, 1204 (Oguti, 1993). Moreover, the person who wrote the historical document and the place where it was recorded, were clear. In both documents, the time, the expression, and the color of the SEKKI appearance were described in detail.

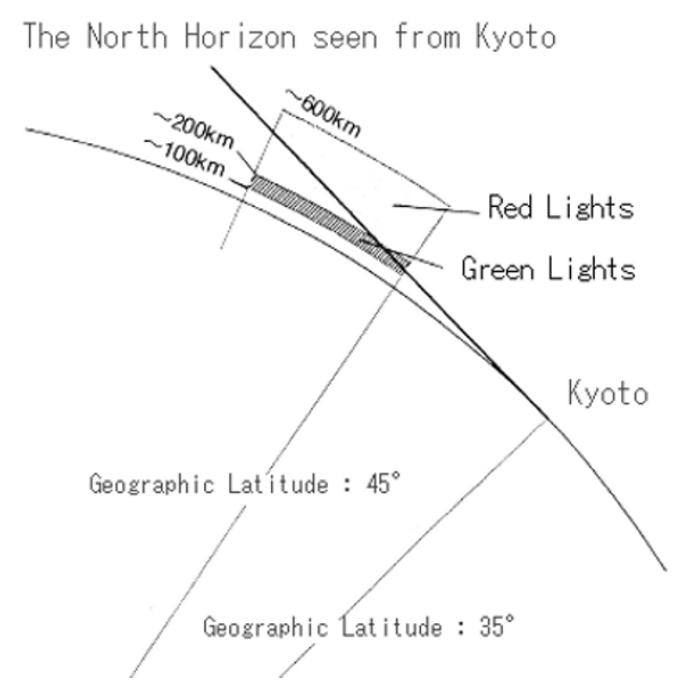

Fig. 2. Geographical relation between the location of the low-latitude aurora and the observation point (in case of Kyoto).

\subsection{The SEKKI Event of February 21, 1204}

Fujiwara no Teika (1162-1241) is the famous Japanese poet, who lived in Kyoto and edited the "Shin-kokinwakasyu" (Japanese poem "Waka"). He recorded the Super Nova in Taurus observed on 1054 in his diary "Meigekki" (or "Meigetsuki"). Teika was the excellent astronomical recorder in those days.

In Meigekki, Teika described the SEKKI of February 21, 1204, as "After lighting a candle, the SEKKI appeared in the direction of the north to the northeast. It extended further and was likely to be watching a distant fire. There were four or five white places and three or four red fiber-like structures in it. The lights did not become weak at all, and the red lights overlapped each other with the white lights. It was a very strange and fearful sight." Two days later, he again wrote "After lighting a candle, the SEKKI appeared in the direction of the north to the northeast again. It seemed to be a fire. It was really terrible over and over again."

According to "Omuro-sosyoki" (The Kamakura Period in Kyoto), on February 21, 1204, "White lights overlapped with the red lights at about 8 p.m. It was observed from WNW to ENE. In the next night, it extended over the north direction from ENE in the same way. White lights were not seen. It was also the same two days later. It was really a rare event in the world" (Kanda, 1935; Nakazawa, 1999).

The points of these two historical documents are,

- The season (February) was the early spring when the occurrence of magnetic storms has a peak in the present era (Russell and McPherron, 1973; Cliver et al., 2000).

- The SEKKI had an extent of about 120 degrees centered around the north.

- White lights (the fiber-like structures of the lights) were seen clearly in the red lights.

- The SEKKI on the second night is considered to be a SAR arc, which is a kind of red aurora during the recovery phase of storm, because the white lights were not observed on the second night in Kyoto. The SAR 
Table 1. 16 examples of "SEKKI" phenomena.

\begin{tabular}{|c|c|c|c|c|c|c|}
\hline No. & Date & Local Time & Place & Description & Direction & Notes \\
\hline 1 & Aug. 12,1150 & (night) & Kyoto & "SEKKI" & north-northeast & \\
\hline 2 & Oct. 08,1150 & 4 a.m. & Kyoto & “SEKKI" & north-west & \\
\hline 3 & Dec. 19,1202 & 8 p.m. & Kyoto & "SEKKI" & - & \\
\hline 4 & Feb. 21, 1204 & 8 p.m. & Kyoto & "SEKKI" & north-northeast & \\
\hline 5 & Aug. 10, 1247 & 10 p.m. & Kyoto & "SEKKI" & north & \\
\hline 6 & Jul. 30, 1363 & (night) & Kyoto & “SEKKI" & north-northeast & \\
\hline 7 & Oct. 27,1370 & 8 p.m. & Kyoto & "SEKKI" & north & \\
\hline 8 & Nov. 25,1370 & 0-4 a.m. & Kyoto & "SEKKI" & north & \\
\hline 9 & Oct.,- 1371 & (night) & Kyoto & “SEKKI" & north & \\
\hline 10 & Mar. 02, 1653 & - & “Edo” (Tokyo) & "SEKKI" & - & \\
\hline 11 & Sep. 17, 1672 & - & Kyoto & "TEN-AKA-shi" & - & \\
\hline 12 & Feb. 15,1730 & (night) & "Kaga" (Kanazawa) & “KOHKI" & northwest-east & $* 1$ \\
\hline 13 & Sep. 17,1770 & 6:30 p.m. to dawn & various regions & "SEKKI”, "KOHKI” & northwest-northeast & $* 2$ \\
\hline 14 & Sep. 25,1770 & 10 p.m. & Kyoto & "SEKKI" & west & \\
\hline 15 & Jan. 06, 1781 & 6-8 p.m. & "Shimosa" (Chiba) & “SEKKI" & north-northwest & $* 3$ \\
\hline 16 & Sep. 02, 1859 & 7 p.m. to midnight & “Kii” (Wakayama) & “SEKKI" & north & $* 4$ \\
\hline
\end{tabular}

Place: Kyoto: geographic latitude $=35.0^{\circ} \mathrm{N}$; Tokyo: geographic latitude $=35.7^{\circ} \mathrm{N}$; Kanazawa: geographic latitude $=36.6^{\circ} \mathrm{N}$; Chiba: geographic latitude $=35.6^{\circ} \mathrm{N}$; Wakayama: geographic latitude $=34.2^{\circ} \mathrm{N}$.

Notes: *1: Solar activities became maximum in 1727.; *2: Solar max in 1769.; *3: Solar max in 1778.; *4: Solar max in 1860.

arc was probably developed significantly to be visible by naked eyes.

In order to form the fiber-like structures in auroras, it is necessary to see the red lights (typical altitude: 200-600 $\mathrm{km})$ in the back through the green lights (100-200 km) from the sky of Kyoto. Figure 2 shows possible configuration of low-latitude auroras appeared at latitudes higher than Kyoto. The low-latitude boundary of aurora must be at latitudes $\sim 7^{\circ}-10^{\circ}$ and $\sim 10^{\circ}-14^{\circ}$ north of Kyoto (geographic latitude $=35.0^{\circ} \mathrm{N}$ ) for elevation angles of $0^{\circ}$ and $5^{\circ}$ from the northern horizon, respectively, by assuming auroral altitudes of 100-200 km. Thus, the aurora would be located from the northern part of Hokkaido (geographic latitude $=45^{\circ} \mathrm{N}$ ) to the southern part of Sakhalin.

From the above considerations, the historical descriptions of the SEKKI event of February 21, 1204, are quite likely to be the definite records of a giant low-latitude aurora that happened in the beginning of the 13th century when solar activity was very high and the magnetic north pole was slanted toward the northeastern Asia.

\subsection{The SEKKI event of September 17, 1770}

The SEKKI event of September 17, 1770, took a special attention in the early modern records, because it was observed over a broad area from Hokkaido (northern Japan) to Kyushu (southern Japan). About 40 records of this event were left in historical literatures.

According to "Zoku-shigusyo" (1798 in Kyoto), the SEKKI appeared in the sky from northeast to northwest of Kyoto. Because the SEKKI was so bright, people could see their face each other even in the dark night. The color of SEKKI was like a fire, and some fiber-like structures of the white light extended from the north to the south at about 10 p.m. The SEKKI was continuously seen until dawn, though

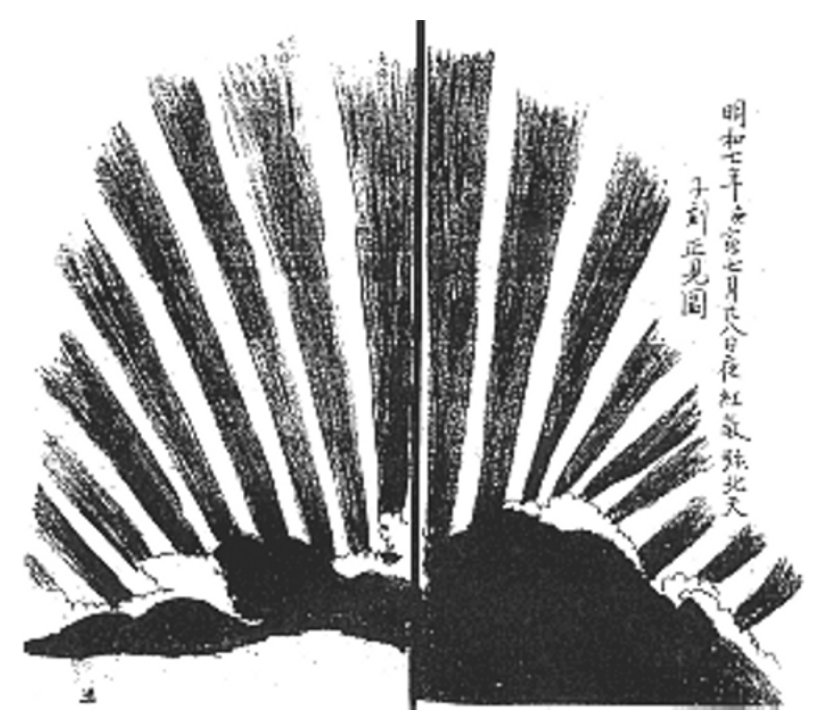

Fig. 3. The schematic picture in "Seikai" from Kano-bunko collection of the library of the Tohoku University (copied from a microfilm).

white fiber-like structures disappeared soon.

In "Echigo-no-kuni-nendaiki" (1866, Niigata Prefectural Library possession) described that the northern sky turned red and looked like a fire. More than 50 white snakes appeared in the red emissions streaming north and south (Niigata: geographic latitude $=37.9^{\circ} \mathrm{N}$ ).

For this SEKKI event, a schematic picture was drawn in "Seikai" (1858), as shown in Fig. 3. The SEKKI was drawn in the vermilion radial-shaped structures. The structures were called "KOHKI" in the literature, which means red emission in Japanese (Ohsaki, 1994; Nakazawa, 1999).

The points of these historical documents are, 
- Solar activity became maximum in 1769 (one year before the SEKKI event).

- The season was the autumn when the occurrence of magnetic storms has a peak.

- These historical documents show characteristics of lowlatitude auroras that the vertical stripe pattern, which looks whitish, appeared embedded on dark red lights. The description of Echigo-no-kuni-nendaiki gives the impression of the polar aurora, which sometimes looks like streaming white snakes.

It is also interesting to note the longitudinal (east-west) motion of SEKKI in the literatures. According to "Tsugaruhenran-nikki" (1793, Hirosaki City Library possession), red clouds that looked like a fire extended from west to north about 6:30 p.m. About 10 p.m. it gradually moved to the east, became farther red (Hirosaki: geographic latitude $\left.=40.6^{\circ} \mathrm{N}\right)$. Such feature was also described in other literatures (Ohsaki, 1994). Similar longitudinal motions were reported in the modern auroral observations by all-sky auroral imager during the low-latitude aurora events of February 27, 1992 and May 10, 1992 (Shiokawa et al., 1994). These longitudinal motions may be related to the longitudinal development of disturbances in the magnetosphere during magnetic storms.

From the above considerations, the SEKKI event of September 17, 1770, probably corresponds to a large-scale long-lasting low-latitude aurora. Considering that the magnetic north pole was in the north American sector like that in the present day (Oguti, 1993), the SEKKI event of September 17,1770 , may be related to the extremely intense magnetic storm.

\section{Conclusions}

From the detailed investigation of SEKKI events described in the historical literatures, we obtained the following conclusions.

(1) There have been many SEKKI descriptions since AD620 in the Japanese historical literatures.

(2) Detailed descriptions were recorded in the two SEKKI events of February 21, 1204, and September 17, 1770. We conclude that these events were large-scale appearance of low-latitude auroras.

Because Japan is located far from the auroral zone latitudes, continuous measurements of auroras from Japan will be very important in order to investigate physical process in the inner magnetosphere that produces spectacular lowlatitude auroras.

Acknowledgments. This paper is based on the thesis for the Master's degree (December 2003) of the graduate school of the University of the Air. We were supported by Prof. Dai-ichiro Sugimoto of the University of the Air, who guided this research, Dr. Kimiaki Masuda of the Solar-Terrestrial Environment Laboratory, Nagoya University, who supplied the data of C14, and Mr. Shigeyoshi Oda- giri of the Aomori prefectural Aomori-Minami high school, who had documents for historical literatures of Aomori Prefecture. We are also grateful to the public and university libraries for supplying the historical data, i.e., Tohoku University Library, Niigata University Library, Niigata Prefectural Library, and Hirosaki City Library.

\section{References}

Cliver, E., Y. Kamide, and A. Ling, Mountains versus valleys: Semiannual variation of geomagnetic activity, J. Geophys. Res., 105(A2), 2413-2424, 2000 .

Furuhata, M., Aurora and airglow observations on February 11, 1958, Rep. Ionos. Res. Jpn, 12, 40-41, 1958.

Hikosaka, T., On the great enhancement of the line [OI] 6300 in the aurora at Niigata on February 11, 1958, Rep. Ionos. Res. Jpn, 12, 469-471, 1958.

Kakioka Magnetic Observatory, Report of the auroras observed at Memambetsu through 1958 and 1960, Report of the geomagnetic and geoelectric observations, No. 8, 109-130, 1967, 1969.

Kanda, S. (ed.), Nihon-tenmon-shiryo, 8: Zassyo, 4: SEKKI, Hara-shobo, $1935,1978$.

Masuda, K., STEL-Newsletter, 21, 1-3, Solar-Terrestrial Environment Laboratory, Nagoya University, 2000.

Miyaoka, H., T. Hirasawa, K. Yumoto, and Y. Tanaka, Low latitude aurorae on October 21, 1989. I, Proc. of the Jpn. Acad., 66, 47-51, 1990.

Nakazawa, Y., List of the Low-Latitude Auroras Observed in Japan, The Astronomical Herald, 92, 2, 94-101, Astronomical Society of Japan, 1999.

Oguti, T., The Auroral Zone in Historic Times-The Northern UK was in the Auroral Zone 300 Years Ago, J. Geomag. Geoelectr., 45, 231-242, 1993.

Ohsaki, S. (ed.), Kinsei-nihon-tenmon-shiryo, 10: Zassyo, 5: SEKKI, Harashobo, 1994.

Okada, T., H. Hayakawa, K. Tsuruda, A. Nishida, and A. Matsuoka, EXOS $\mathrm{D}$ observations of enhanced electric fields during the giant magnetic storm in March 1989, J. Geophys. Res., 98, 15,417-15,424, 1993.

Russel, C. T., and R. L. McPherron, Semiannual variation of geomagnetic activity, J. Geophys. Res., 78, 92-108, 1973.

Saito, B., Y. Kiyama, and T. Takahasi, Spectral Characteristics of LowLatitude Auroras Observed from Japan on February 11, 1958 and on May 10, 1992, J. Geomag. Geoelectr., 46, 253-262, 1994.

Shiokawa, K., K. Yumoto, Y. Tanaka, T. Oguti, and Y. Kiyama, Low-latitude auroras observed at Moshiri and Rikubetsu $(\mathrm{L}=1.6)$ during magnetic storms on February 26, 27, 29, and May 10, 1992, J. Geomag. Geoelectr., 46, 231-252, 1994.

Shiokawa, K., K. Yumoto, Y. Tanaka, Y. Kiyama, Y. Kamide, and M. Tokumaru, A low-latitude aurora observed at Rikubetsu $(\mathrm{L}=1.6)$ during the magnetic storm of September 13, 1993, Proc. NIPR Symp. Upper Atmos. Phys., 8, 17-23, 1995.

Shiokawa, K., C.-I. Meng, G. D. Reeves, F. J. Rich, and K. Yumoto, A multievent study of broadband electrons observed by the DMSP satellites and their relation to red aurora observed at midlatitude stations, J. Geophys. Res., 102, 14,237-14,253, 1997.

Shiokawa, K., R. R. Anderson, I. A. Daglis, W. J. Hughes, and J. R. Wygant, Simultaneous DMSP and CRRES observation of broadband electrons during a storm-time substorm on March 25, 1991, Phys. Chem. Earth, 24, 281-285, 1999.

Shiokawa, K., T. Ogawa, and Y. Kamide, Low-latitude auroras observed in Japan during the solar maximum period of 1999-2003, J. Geophys. Res., 2004 (submitted).

Stuiver, M., P. J. Reimer, and T. F. Braziunas, Decadal $\Delta 14 \mathrm{C}$ variation, Radiocarbon, 40, 1127, 1998.

Taguchi, T., Nihon no rekishi-jidai no kiko ni tsuite (3), Cyosa 4: Kyokkoshiryo, 1939, edited by Chuo-kisyodai/Kaiyo-kisyodai, in Nihon no Kisyo-shiryo 3, 1941, Hara-syobo, 1976.

Y. Nakazawa (e-mail: nakazawa.yoh@nifty.ne.jp), T. Okada, and K. Shiokawa 